\title{
Inter-Disciplinary Conservative Management of Bilateral Non- United Lumbar Pars Defects in a Junior Elite Golfer
}

\author{
Simon L Brearley ${ }^{1}$, Orlaith Buckley², Patrick Gillham ${ }^{3}$, Bryan Clements ${ }^{4}$, Daniel Coughlan ${ }^{5}$ \\ ${ }^{1}$ Cranleigh School; England Golf; European Tour Performance Institute, ${ }^{2}$ European Tour Performance Institute, ${ }^{3}$ Pure Sports Medicine, ${ }^{4}$ Cranleigh \\ School, 5 University College London \\ Keywords: exercise, spondylolysis, rehabilitation, golf
}

https://doi.org/10.26603/001c.18873

International Journal of Sports Physical Therapy

Vol. 16, Issue 1, 2021

\begin{abstract}
The prevalence of spondylolysis amongst adolescent athletes presenting with low back pain has been reported as high as $47-55 \%$. Youth athletes participating in sports involving movements combining compression, extension and rotation appear most susceptible. As such, young golfers are a high-risk group, particularly given the high shear and compressive forces associated with the golf swing action. This is compounded by a culture which encourages very high practice volumes, typically poorly monitored. Although non-operative interventions are deemed the gold-standard management for this condition, surgery is indicated for more severe presentations and cases of 'failed' conservative management. The case presented herein outlines an inter-disciplinary, non-operative management of a 17-year old elite golfer with a moderate to severe presentation. A 4-stage model of reconditioning is outlined, which may be of use to practitioners given the paucity of rehabilitation guidelines for this condition. The report highlights the benefits of a graded program of exercise-based rehabilitation over the typically prescribed " 12 weeks rest" prior to a return to the provocative activity. It also supports existing evidence that passive therapeutic approaches should only be used as an adjunct to exercise, if at all in the management of spondylolysis. Finally, and crucially, it also underlines that to deem non-surgical rehabilitation 'unsuccessful' or 'failed', clinicians should ensure that (long-term) exercise was included in the conservative approach.
\end{abstract}

\section{Level of Evidence}

4-Case Report

\section{INTRODUCTION/BACKGROUND}

Spondylolysis is a defect in the pars interarticularis of a vertebra. The pars interarticularis is a small isthmus of bone between the superior and inferior articular facets of spinal vertebra. ${ }^{1}$ The fracture can be unilateral or bilateral and although any spinal level may be affected, $71 \%$ to $95 \%$ of lesions occur at $\mathrm{L} 5$ and $5 \%$ to $23 \%$ at $\mathrm{L} 4 .^{2,3}$ The cause is most commonly a fatigue fracture, as a result of higher stress loads with movements combining compression and extension or rotation. ${ }^{4}$ The injury starts as a stress fracture, and can develop into a full fracture, non-union, and eventually a spondylolythesis. ${ }^{2,5}$ Spondylolysis most commonly occurs in sports involving these movements, for example gymnas- tics, cricket, tennis, golf, football, hockey, athletics, swimming, and basketball. ${ }^{5-8}$

Spondylolysis has a reported incidence of $6 \%$ in the general adult population and $4.4 \%$ in the paediatric population as a cause of low back pain. ${ }^{9}$ In the sporting population incidence of spondylolysis has been reported as high as 47-55\% in adolescent athletes presenting with low back pain. ${ }^{5}$ Early diagnosis is important to prevent non-union which has been associated with an increased incidence of spondylolisthesis. ${ }^{5}$ Moreover, earlier recognition of acute spondylolysis is associated with improved fracture healing. ${ }^{2}$

Due to the anatomy of the sacral angle and the inferior facet of L5, a large anterior shear on the L5 pars interarticularis is created. In young athletes, the spine is undergoing

\footnotetext{
a Corresponding author:

Simon Brearley

Cranleigh School

Annexe, Field view, Upfold ln

Cranleigh, UK GU68PD

simonlbrearley@gmail.com
} 
growth and re-modelling with full bony maturation of the pars interarticularis not occurring until the age of $25 .^{3}$ The anterior shear, along with bony immaturity of adolescence are thought to be two of the greatest contributing factors making spondylolysis more common in the adolescent population. ${ }^{2}$

Individuals who stand with an excessive anterior pelvic tilt will increase the anterior shear at the L5 level, therefore increasing the risk for spondylolysis at L5. ${ }^{2}$ It has been proposed this may be emphasized in adolescents presenting with lower abdominal weakness; hip flexor, hamstring and thoracolumbar fascial hypertonicity; increased femoral anteversion; genu recurvatum, and increased thoracic kyphosis. ${ }^{2,3,6,8,10}$ Reduced hip-lumbar and thoracolumbar dissociation is also a common trait in adolescent athletes. ${ }^{8} \mathrm{~A}$ higher body mass index is also associated with a higher lumbar lordosis. ${ }^{11}$

Other factors likely to increase the risk for youth golfers specifically are both biomechanical and load related. Given the growing importance of driving distance players may adopt techniques which increase the stress at the lumbar spine in pursuit of greater club head speed (CHS) e.g. seeking a large rotation of the torso relative to the pelvis, commonly referred to in the literature as the 'X-Factor'. ${ }^{12-15}$ Combining such techniques with high and poorly monitored volumes (often spiked in response to a step up in level i.e. selection for a regional or national squad) is likely to increase the chances of developing spondylolysis. Indeed, it is not uncommon for age-group regional level golfers to perform up to 1000 swings per week with considerable variations in golf volume across the year, seemingly driven by exam periods. ${ }^{16}$ The variability of volume is an important point to note given previous research has shown this to be more predictive of injury than volume alone. ${ }^{17}$

The current gold standard for investigating and diagnosing spondylolysis is bone scintigraphy with SPECT (single photon emission computed tomography). This should be complimented with thin sliced reverse-gantry axial computed tomography (CT) if bone scintigraphy is positive. ${ }^{5}$ Magnetic resonance imaging (MRI) has many useful advantages including being non-invasive, and an absence of ionising radiation. However, the use of MRI for first-line investigation has shown a significant number of false-negative scans. 5,9

Research stipulates that conservative management for these patients is the gold standard for adolescents with lumbar spondylolysis in preference to surgical interventions. ${ }^{18}$ In fact, adolescent athletes return to play $92.2 \%$ of the time with nonoperative management, compared to $90.3 \%$ when treated surgically. ${ }^{18}$ Surgical intervention is indicated if there is failure of conservative treatment after 6 months, persistent back pain after 9-12months, or nonunion after 9-12months. ${ }^{11}$ Other relative indicators for surgical management are in athletes with spondylolisthesis of more than $50 \%$ in those who have not reached skeletal maturity, neurological deficit with continued lumbar spine pain, and vertebral instability. 8,11 A mean time for returnto-play following surgical intervention is 7.9 months. ${ }^{11}$

Evidence by Sundell et al ${ }^{19}$ highlights that early stage stress reactions of the pars interarticularis will heal with 3 months of rest from physical activity with no restrictions in activities of daily living and without a brace. Early stages were seen to heal quicker than late stages, which highlights the importance of early diagnosis. Having reviewed the literature, both Tawfik et al. ${ }^{11}$ and Panteliadis et al. ${ }^{20}$ both agreed with a mean return-to-play of 3.7 months following conservative treatment of bracing, rest, and rehabilitation in the form of strength and flexibility. Rehabilitation in 25 ice hockey players with spondylolysis aged between 15-18 years were rehabilitated conservatively using rest from physical activity, core strength, flexibility, and anti-lordotic stabilisation in particular. ${ }^{6}$ Return-to-play ranged from 6 to 12 weeks with an average of eight weeks.

Currently, to the authors knowledge there are no case reports outlining the rehabilitation and reconditioning of spondylolysis in adolescents. The purpose of this case report is to outline a structured guideline for rehabilitation during the commonly ordered 12 -week rest from the instigating/provocative activity.

\section{CASE DESCRIPTION}

The athlete (male, age: 15years; stature: $1.75 \mathrm{~m}$; body mass: $66 \mathrm{Kg}$ [initial assessment]) presented to England Golf regional squad training in the autumn of 2015 (provided as a part of the England Golf Union performance support program) reporting ongoing ( 12 weeks duration) low back pain of gradual onset which had not improved with acupuncture and manual therapy, received from another provider. He had a golf handicap of three strokes but was unable to play competitively over the previous summer due to back pain. As a result, his parents were seeking a second opinion regarding treatment options and were awaiting referral to orthopedics. In the meantime he rested intermittently from golf which alleviated symptoms but pain consistently returned on return to the activity.

The initial orthopedic consultant to review the case (October 2015) suspected no bony injury and the patient was reassured. However, persistence of symptoms led to referral for MRI in March 2016. The MRI showed pars fractures bilaterally with $1 \mathrm{~mm}$ and $2 \mathrm{~mm}$ defects both at acute angles. He was advised to rest for 12 weeks to promote recovery but a follow up CT scan in June 2016 showed little evidence of healing bilaterally. A primary posterior fusion to stabilize the non-united L1 vertebrae was therefore suggested. At this juncture his parents sourced a second orthopedic opinion in July 2016. Review of previous MRI revealed further non-united bilateral pars defect at L5, together with those previously identified at L1. These were larger than the L1 defects, measuring approximately $7 \mathrm{~mm}$ and $8 \mathrm{~mm}$ respectively (Figure 1). Concern was also expressed about a slight L5/S1 listhesis. Accordingly, steroid injections were proposed together with a pain diary during an experimental return to play phase, to differentiate which defect was causing the pain. Spinal fusion was discussed as the preferred surgical option, despite the chance of a rotational hypomobility which may prevent further participation in competitive golf. 


\section{INITIAL EXAMINATION}

\section{SUBJECTIVE}

The athlete was assessed by the support team physiotherapist in September 2016, with a view to exploring all nonsurgical and surgical options. The steroid injections were already booked at the time of the assessment, as the consultants felt all non-surgical options had been exhausted. However, an in-depth review of the athlete's history revealed that no structured exercise-based rehabilitation plan had been adhered to.

\section{OBJECTIVE ASSESSMENT}

An 11-point numerical pain rating scale (NPRS), where $0=$ no pain and $10=$ worst pain imaginable, was used to objectively measure the pain the subject was experiencing in different tasks. At rest the athlete was pain-free. During short swims pain increased to $7 / 10$, and took two to three hours to resolve completely.

On assessment, the athlete had minimal pain in standing, yet golf 'address' posture caused pain to rapidly increase to $7 / 10$. His lumbar spine range of movement (ROM) was normal in flexion and extension. Right and left side lumbar flexion increased pain, 2/10 bilaterally. There was full ROM bilaterally in hips and knees, and through thoracic spine flexion. Extension was stiff and occurred at the thoracolumbar region together with rib flare but there was no loss in ROM. Seated thoracic spine rotation caused some apprehension but no pain. Right rotation was slightly limited in comparison to the left at end ROM. There was increased muscular development visible in the right lumbar paravertebral.

Further assessment was informed by the movement demands of the sport and previous research highlighting the predisposing biomechanical and postural factors for lumbar spine stress fractures, discussed previously. Accordingly, this centered around assessment of inter-segmental control of thorax on pelvis in anatomical positions relevant to the sport i.e. hip hinge with overhead shoulder movement (particularly flexion/abduction external rotation). Initial observation revealed poor lumbar-extension (shelving), pelvicthorax (ribcage flaring), and cervical extension (poking chin) control during hinging and this movement produced hypertonicity in the paravertebrals together with a general apprehension, all of which were further pronounced by the addition of increasing shoulder flexion/abduction. Moreover, there was poor dissociation of the pelvis on the torso (and vice versa) with a lateral hip shift and a compensatory lateral flexion with rib flare occurring when trying to rotate the torso independently. Finally, although the subject had full ROM in anterior to posterior pelvic tilt, active control was poor - likely a habituated behavior secondary to pain or threat of pain. ${ }^{21}$

These findings were triangulated with the golf coach's more specific (swing) movement analysis which combined basic motion capture techniques using a high-speed camera, review of historical footage and coaching eye. Subsequently, the following assessment points were agreed on relating to technical aspects which may have contributed to the development of the injury:

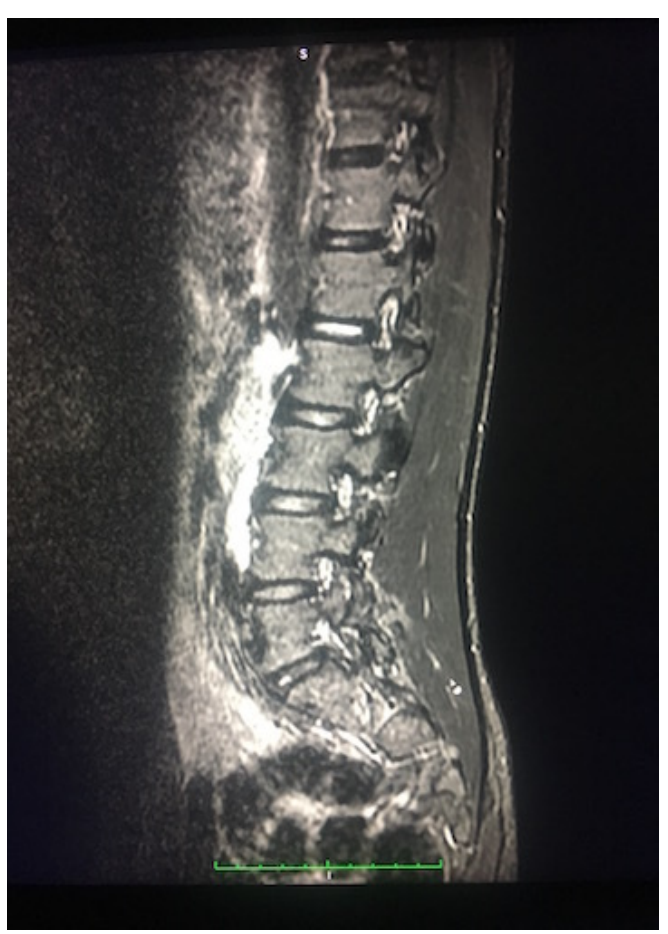

Figure 1: MRI demonstrating bilateral pars defects at L1 and L5 with possible slight L5/S1 listhesis.

- Excessive (spinal) extension and scapulae elevation with overly high muscle activity of the neck and paraspinals at address and into takeaway;

- Compensatory lateral (spinal) flexion and lateral hip shift during rotation (backswing);

- Excessive "crunch factor" - lateral spinal flexion through impact;

- Substitution of (or concomitant) lumbar extension for hip extension during the acceleration phase, impact and follow through.

\section{INTERVENTION PLAN}

Both the athlete and his parents were advised that longterm exercise-based rehabilitation should be given a fair chance before consideration of surgery. Expectations were managed by proposing a 12-month timeline for the plan upfront. Inter-disciplinary input was deemed important and therefore performance support experts were recruited from the disciplines of Coaching/Biomechanics and Strength and Conditioning (S\&C) to support Physiotherapy. Given the outcomes of these respective initial assessments, the overarching plan was to both reduce load going through the injured region during the golf swing, while increasing the load the athlete can tolerate to provide further insurance. At this juncture both the athlete and his parents gave informed consent to participate and for the data collected during the intervention to be published. The study was subsequently approved by the University of Essex ethics board.

\section{PHASE 1: ACUTE}

During the first few weeks of this phase all other physical 
Table 1: Phase 1: Acute Rehabilitation Program

\begin{tabular}{|l|l|l|}
\hline \multicolumn{2}{|c|}{ Program of Rehabilitation. Phase 1: Acute } \\
\hline \multicolumn{1}{|c|}{ Motor Control } & \multicolumn{1}{|c|}{ Intended Physical Outcome } & \\
\hline 1 & Hip Hinge with Dowel & Motor control \\
\hline $2 \mathrm{a}$ & Modified Dead Bugs - Wall Heel Taps & Segmental stabilization \\
\hline $3 a$ & Hip Hinge with band crab walks & Motor control / lateral hip stability \\
\hline $2 \mathrm{~b}$ & Modified Dead Bugs with Wall Heel Tap Arcs & Segmental stabilization \\
\hline $3 \mathrm{~b}$ & Hip Hinge band crab walks in split stance & Motor control / lateral hip stability \\
\hline${ }^{*} 2 \mathrm{~b} \&$ 3b were progressions added upon mastery of 2a/3a & \\
\hline
\end{tabular}

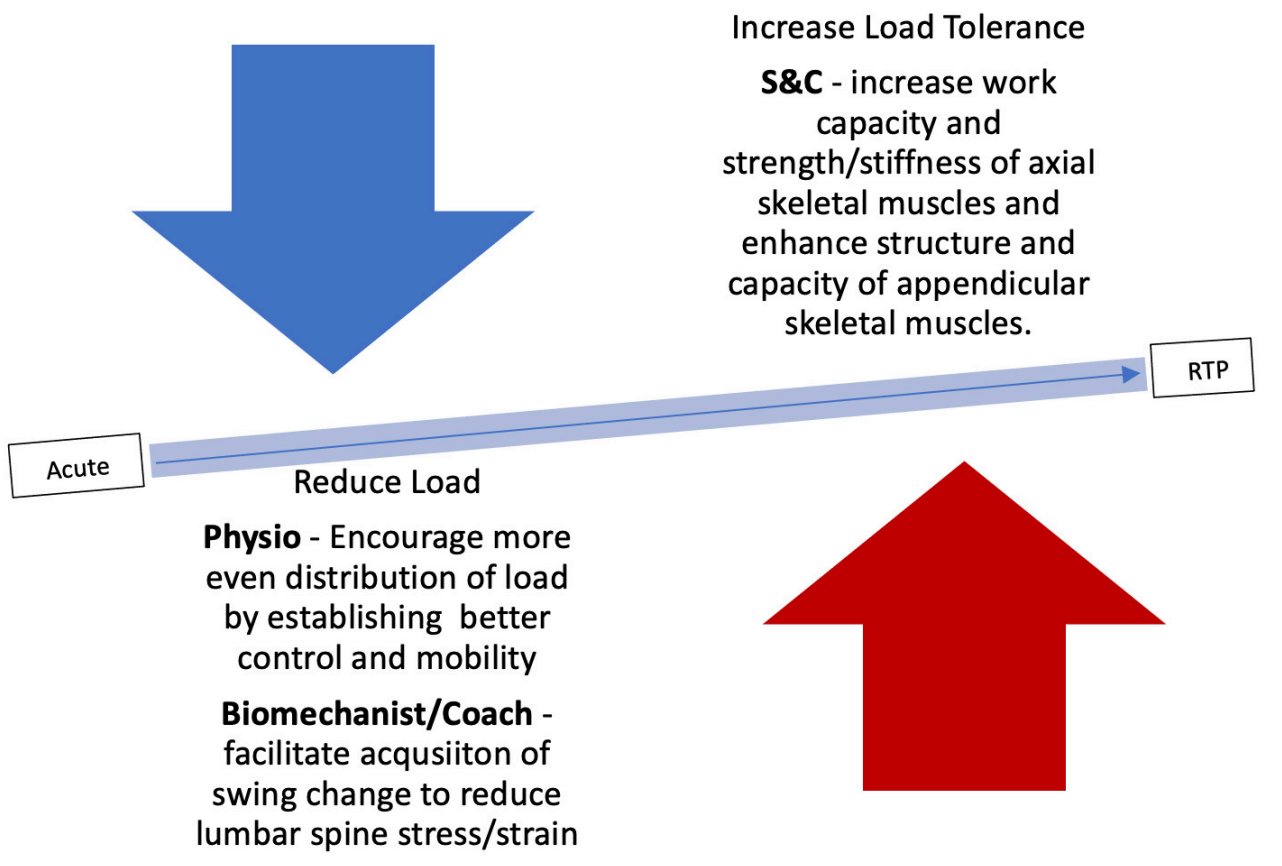

Figure 2: Inter-disciplinary conservative management / rehabilitation plan showing increasing emphasis on load tolerance towards return to play. (S \& C refers to strength and conditioning specialist)

activity was restricted apart from the rehabilitation program itself. As soon as the subject was pain-free into lumbar extension stationary cycling was introduced to maintain cardio-respiratory fitness and mental wellbeing. Program design at this stage was led by the physiotherapist with the emphasis on reducing biomechanical load subjected to the lumbar spine by improving inter-segmental control and mobility (lower limb flexibility/muscle extensibility, thoracic spine extension and rotation), establishing hip-lumbar and lumbar-thoracic dissociation, and increasing the subject's overall kinaesthetic awareness of their posture. Table 1 shows what exercise-based solutions were used to address this.

To the authors knowledge, there is little evidence regarding specific criteria for graduated return to play in adolescents. Notwithstanding, the support team valued setting visible, achievable milestones throughout the rehabilita- tion process for motivation purposes. Therefore although experiential in nature (as recommended by the authors), exit-criteria for this phase was as follows:

-Able to walk 18 holes without pain during or after;

-Able to cycle 20 mins rating of perceived exertion (RPE) 6 without pain during or after;

-Pain-free lumbar extension and stork test;

-Reduced movement guarding and apprehension;

-Well dissociated pain-free repeated bodyweight (BW) hinge in kneeling and standing without kinetic chain compensations observed at initial assessment.

\section{PHASE 2: SUB-ACUTE/LOAD INTRODUCTION}

It was at this phase that coach collaboration became a pivotal part of the rehabilitation process as the team were keen to re-introduce controlled putting practice. This was monitored via 'time on green' and periodically interrupted 
Table 2: Phase 2: Sub-Acute Load Intro Rehabilitation Program

\begin{tabular}{|c|c|c|c|c|c|}
\hline \multicolumn{6}{|c|}{ Program of Rehabilitation: Phase 2: Sub-Acute / Load Intro } \\
\hline \multicolumn{2}{|c|}{ Mobility \& control } & Set & Rep & Rest & Intended physical outcome \\
\hline $1 a$ & DB split squat (trail leg focus) & 3 & $6 \mid 6$ & $30 \mathrm{~s}$ & Hip strength \& mobility \\
\hline $1 b$ & Open the book & 3 & $8 \mid 8$ & $30 \mathrm{~s}$ & Thoracic rotation mobility \\
\hline $2 a$ & Band assisted OHS & 3 & $6-8$ & $30 \mathrm{~s}$ & Thoracic extension mobility / pelvic-thorax control \\
\hline $2 b$ & MB lunge with rotation & 3 & $6 \mid 6$ & $30 \mathrm{~s}$ & Spinal dissociation / thoracic rotation mobility \\
\hline $3 a$ & Kneeling hip hinge & 3 & $6-8$ & $30 \mathrm{~s}$ & $\begin{array}{l}\text { Hip-lumbar dissociation / local loading / gluteal } \\
\text { strength }\end{array}$ \\
\hline $3 b$ & $\begin{array}{l}\text { Standing hip hinge with } \\
\text { shoulder ext. rotation }\end{array}$ & 2 & $6-8$ & $30 \mathrm{~s}$ & $\begin{array}{l}\text { Hip-lumbar dissociation / local loading / external } \\
\text { rotation strength/mobility }\end{array}$ \\
\hline $3 c$ & Wall angels & 2 & $6-8$ & $30 \mathrm{~s}$ & Thoracic extensor mobility / pelvic-thorax control \\
\hline \multicolumn{2}{|c|}{ 'Pillar' work capacity } & Set & TUT & Rest & Notes \\
\hline 1 & Supine band pullover hold & 3 & $20-90 s$ & $30 \mathrm{~s}$ & $\uparrow$ metabolic capacity of anterior trunk musculature \\
\hline 2 & Glute bridge series & 3 & $20-90 s$ & $30 \mathrm{~s}$ & $\uparrow$ metabolic capacity of posterior hip musculature \\
\hline 3 & Pallof series & 3 & $20-90 s$ & $30 \mathrm{~s}$ & $\begin{array}{l}\uparrow \text { metabolic capacity of anterior trunk/rotation } \\
\text { muscle }\end{array}$ \\
\hline 4 & Prone extension & 3 & $20-90 s$ & $30 \mathrm{~s}$ & $\begin{array}{l}\uparrow \text { metabolic capacity of posterior trunk } \\
\text { musculature }\end{array}$ \\
\hline \multicolumn{6}{|c|}{ Microprogram } \\
\hline \multicolumn{2}{|c|}{ Control } & Set & Rep & Rest & Notes \\
\hline 1 & Superman series & N/ & N/A & N/ & Segmental stabilization / spinal dissociation \\
\hline 2 & $\begin{array}{l}\text { Modified dead bugs with wall } \\
\text { heel taps }\end{array}$ & $\mathrm{N} /$ & N/A & $\mathrm{N} /$ & Segmental stabilization \\
\hline 3 & $\begin{array}{l}\text { Hip Hinge band crab walks in } \\
\text { split stance }\end{array}$ & $\mathrm{N} /$ & N/A & N/ & Motor control / lateral hip stability \\
\hline
\end{tabular}

with 'movement breaks' which consisted of progressions and variations of phase- 1 motor control drills which now formed a 'micro-program'. This was essentially a minimalist program which the subject performed daily alongside a newly introduced strength and conditioning $(\mathrm{S} \& \mathrm{C})$ program which was performed 2-3x per week.

A key factor determining the spinal stability strategy deployed by the central nervous system is the magnitude of imposed load, ${ }^{21,22}$ with increasing motor unit recruitment of (superficial) muscles with higher contractile potential as task demands surpass the force thresholds of the (deep) muscles attached to the spinal column. ${ }^{23,24}$ Presence of pain or perceived threat to stability disrupts this governance, with delayed trunk-muscle reflex responses and excessive/early superficial motor unit recruitment. ${ }^{25-27}$ Continuation of the micro-program was therefore deemed important to continue to restore and refine neuromuscular coordination of deep muscle co-contraction, particularly considering the magnitude of load imposed in golf tasks such as walking and putting, is relatively low.

Meanwhile, objectives of the strength and conditioning program were to facilitate the re-distribution of biomechanical load away from the lumbar spine in the golf swing by enhancing the structure and tissue capacities (e.g. increased flexibility, strength, endurance, spinal muscle cross-sectional area etc.) of the appendicular skeleton, as well as increasing the ability of the axial skeleton to tolerate load through graduated spinal load-transfer activity. Indeed, it has been suggested that an even distribution of force is crucial to minimise strain of vulnerable tissues in the spine. ${ }^{28}$ This is particularly important to the golf-drive which involve a high-speed proximal-to-distal sequential sequencing resulting in a summation of forces at the final distal segment. ${ }^{29}$ Insufficient muscular capacity in the proximal lower-limb segments can be responsible for failed load-transfer, ${ }^{21}$ which provides justification for addressing the appendicular skeleton as well as the immediate supporting spinal musculature.

Table 2 outlines how the athlete was subjected to greater control and stability challenges, building on phase- 1 segmental stabilisation exercises with spinal dissociation and segmental control work of the identified areas. Full definitions and classifications of these specific spinal abilities are available in Spencer et $\mathrm{al}^{30}$ consensus statement on spinalexercise prescription in sport. This was followed by a progressive trunk work-capacity program which utilised nonfunctional, isometric 'pillar' exercises to raise the metabolic capacity of the trunk muscles (i.e. increased mitochondria, capillarization, and cross-sectional area etc.), preserving force production and providing greater resistance to fatigue when absorbing, transmitting or dissipating repeated or sustained sub-maximal forces. 
Exit-criteria for this phase was as follows:

- No reaction to introduction of putting practice sessions;

- 2 minute holds on all isometric trunk work capacity assessments (side plank left \& right, double leg lower, prone trunk);

- Maintenance of phase 1 exit criteria.

\section{PHASE 3: RECONDITIONING}

Reconditioning involved a more aggressive pursuit of the objectives outlined in the previous phase having now established greater load tolerance. This allowed for a natural transition to a performance orientated S\&C program addressing the subject's broader athletic development needs while maintaining an emphasis on the development of trunk function. Specifically, this saw a progression from control and work capacity to strength, power and stiffness development (see Figure 3). Again, for full definitions of these physical qualities the reader is directed to Spencer et al. ${ }^{30}$

This phase was split broadly into two with an initial 'accumulation' and an 'intensification block', a training organization concept borrowed from Issurin ${ }^{31}$ where increased capacity in the former prepares the athlete for the intensity in the latter. The initial accumulation phase progressed linearly from moderate to fairly high volumes of work centred around four focus compound lifts - Split Squat, Romanian Deadlift, Barbell Hip Thrust and Trap-Bar Deadlift. Using high-moderate rep-ranges and low to moderate loads initially allowed the subject to become competent and develop coordination in these exercises while increasing their work capacity and stimulating muscle hypertrophy. Focus exercises were generally paired with a stability challenge or a trunk strength exercises and followed by a medicine ball circuit tailored towards trunk stiffness and maintenance of work capacity (Table 3 ). Coach collaboration remained of upmost importance during this accumulation phase as the subject was allowed to return to some wedge play (half back-swing length). Both the athlete and the coach were responsible for monitoring his golf volumes which started at 40 and progressed to 100 swings (wedges) per week.

Following this extensive (12-week) accumulation period the case began an intensification block consisting of moderate-low volumes (3-5 repetitions) of increasing intensities on the focus exercises to drive greater increases in maximal strength (Table 3). An autoregulatory system was used to intensify training throughout the block. This involved assigning a RPE (e.g. 7/10) to each exercise so that the athlete could select a weight that corresponded with that effort level on the specific time/day of the training session. Some studies have found this to produce better training outcomes than fixed loading parameters based on percentage repetition maximums as it possibly yields a higher rate of progressive overload. ${ }^{32}$ Table 4 shows a resource given to the athlete to ensure their understanding of RPE where perceived effort ratings were linked to 'repetitions in reserve'.

\section{PHASE 4: GRADED RETURN TO GOLF (GRTG) PROTOCOL}

Although the athlete had now been subjected to consider-

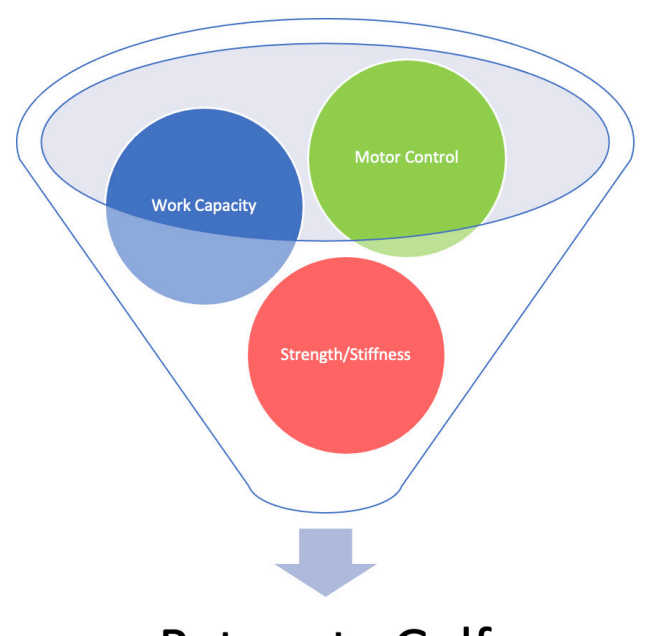

Return to Golf

\section{Figure 3: Multi-dimensional approach to trunk training. Developing foundations of inter-segmental control and work-capacity (Phase 2) before pursuing strength and static rate of force development (stiffness) qualities in the supporting musculature of the axial skeleton.}

able gym training-load, the principle of specificity applies to load tolerance and therefore it was deemed essential to graduate return to pre-injury golf volumes to minimise the chances of relapse/re-entering injury. Moreover, given that the athlete had made a significant swing change, this would have been important regardless of injury history as different movement strategies alter degree of structural loading at specific anatomical sites. The basic principle of the graded return to golf (GRTG) program was to change only one variable at a time. For instance, when increasing intensity (guided by length of backswing or \% max club head speed), no changes were made to number of swings per week. Table 5 shows the first four weeks of the return to golf protocol; beginning with a set number of swings per week initially, before increasing the intensity of those swings (weeks two and three) and then accumulating swings in a given week (week four). This general pattern was repeated until the patient returned to $\sim 75 \%$ of their pre-injury typical weekly volume. Chipping and putting practice were allowed on any other day throughout the return but prolonged practice was avoided at any time. Movement breaks (every $10-15 \mathrm{mins}$ ) were encouraged to avoid prolonged hinging.

\section{OUTCOME}

12-months into the rehabilitation program (Jan 2018) the subject had increased his training loads from $40 \mathrm{Kg}$ (self-selected RPE 8 load for 8 repetitions) to $110 \mathrm{Kg}$ (self-selected RPE 8 load for 5 repetitions) in the Barbell Romanian Deadlift, Barbell Hip Thrust and Trap Bar Deadlift, evidencing large increases in strength and gym-based load tolerance. Moreover, time to failure in the isometric 'pillar' trunk ex- 
Table 3: Phase 3: Reconditioning Program

\begin{tabular}{|c|c|c|c|c|c|c|}
\hline \multicolumn{7}{|c|}{ Program of Rehabilitation: Phase 3: Reconditioning } \\
\hline \multicolumn{2}{|c|}{ Strength-accumulation } & Set & Rep & Rest & RPE & Intended physical outcome \\
\hline $1 \mathrm{a}$ & DB split squat & 3 & $8 / 8$ & $90 \mathrm{~s}$ & 8 & Hip strength \& mobility \\
\hline $1 b$ & $\begin{array}{l}\text { Walking lunge } \mathrm{w} / \text { around the } \\
\text { world }\end{array}$ & 3 & $8 \mid 8$ & $30 \mathrm{~s}$ & N/A & Trunk stability challenge \\
\hline $2 a$ & Trap-bar deadlift & 4 & $8-10$ & $90 \mathrm{~s}$ & 8 & Leg \& trunk strength \\
\hline $2 b$ & Suitcase carry & 3 & $6 \mid 6$ & $30 \mathrm{~s}$ & N/A & Trunk stiffness \\
\hline 3 & BB RDL / BB hip thrust & 4 & $8-10$ & $90 \mathrm{~s}$ & 8 & Leg \& trunk strength \\
\hline \multicolumn{2}{|c|}{ Strength-intensif. } & Set & Rep & Rest & RPE & Intended physical outcome \\
\hline $1 \mathrm{a}$ & RFE split squat & 3 & $6 \mid 6$ & $90 \mathrm{~s}$ & 8 & Hip strength \& mobility \\
\hline $1 b$ & MB lateral bound \& stick & 3 & $6 \mid 6$ & $30 \mathrm{~s}$ & N/A & Trunk stability challenge \\
\hline $2 a$ & Trap-bar deadlift & 4 & 5 & $90 \mathrm{~s}$ & 8 & Leg \& trunk strength \\
\hline $2 b$ & Cable chop & 3 & $6 \mid 6$ & $30 \mathrm{~s}$ & N/A & Trunk strength \\
\hline 3 & BB RDL / BB hip thrust & 4 & 5 & $90 \mathrm{~s}$ & 8 & Leg \& trunk strength \\
\hline \multicolumn{2}{|c|}{ Trunk (Static) RFD } & Set & Rep & Rest & RPE & Intended physical outcome \\
\hline 1 & MB rotary wall rebound throw's & 2 & 10 & $60 \mathrm{~s}$ & N/A & Trunk power (dynamic \& static RFD) \\
\hline 2 & $\begin{array}{l}\text { MB seated wall rebound } \mathrm{OH} \\
\text { throw's }\end{array}$ & 3 & 6 & $60 \mathrm{~s}$ & N/A & Trunk power (dynamic \& static RFD) \\
\hline 3 & MB hinge wall rebound throw's & 3 & $20 \mathrm{~s}$ & $60 \mathrm{~s}$ & N/A & Trunk stiffness \\
\hline 4 & Partner feed kneeling slams & 3 & 5 & $60 \mathrm{~s}$ & N/A & Trunk power (dynamic \& static RFD) \\
\hline 5 & Partner feed plyo russian twist & 2 & $5 / 5$ & $60 \mathrm{~s}$ & N/A & Trunk power (dynamic \& static RFD) \\
\hline 5 & Suitcase carry & 2 & $20 m$ & $60 \mathrm{~s}$ & N/A & Trunk stiffness \\
\hline 6 & Side hold w/ plate press & 2 & $20 \mathrm{~s}$ & $60 \mathrm{~s}$ & N/A & Trunk stiffness \\
\hline \multicolumn{2}{|c|}{ 'Pillar' work capacity } & Set & TUT & Rest & RPE & Intended physical outcome \\
\hline 1 & MB dish sit & 2 & $60 \mathrm{~s}$ & $60 \mathrm{~s}$ & $\mathrm{~N} / \mathrm{A}$ & $\begin{array}{l}\uparrow \text { metabolic capacity of anterior trunk } \\
\text { musculature }\end{array}$ \\
\hline 2 & Banded lateral bear crawl & 2 & $60 \mathrm{~s}$ & $60 \mathrm{~s}$ & N/A & $\begin{array}{l}\uparrow \text { metabolic capacity of trunk/hip } \\
\text { musculature }\end{array}$ \\
\hline 3 & $\begin{array}{l}\text { Asymmetric shoulder raise / } \\
\text { pallof walkout }\end{array}$ & 2 & $60 \mathrm{~s}$ & $60 \mathrm{~s}$ & N/A & $\begin{array}{l}\uparrow \text { metabolic capacity of anterior trunk } \\
\text { /rotation muscle }\end{array}$ \\
\hline 4 & Weighted back extensions & 2 & $60 \mathrm{~s}$ & $60 \mathrm{~s}$ & N/A & $\begin{array}{l}\uparrow \text { metabolic capacity of posterior trunk } \\
\text { musculature }\end{array}$ \\
\hline $\begin{array}{l}\text { DB } \\
\text { exe }\end{array}$ & $\begin{array}{l}\text { ibbell, RFD = rate of force develo } \\
\text { TUT= time under tension }\end{array}$ & & ר, BB & & edic & $\mathrm{I}, \mathrm{OH}=$ overhead, $\mathrm{RPE}=$ rate of perceived \\
\hline
\end{tabular}

Table 4: Rate of perceived exertion (RPE)

\begin{tabular}{|c|c|}
\hline RPE & REPS IN RESERVE \\
\hline 10 & ALL OUT, I HAD NOTHING LEFT \\
\hline 9 & 1 REP LEFT IN THE TANK \\
\hline 8 & 2 REPS LEFT IN THE TANK \\
\hline 7 & 3 REPS LEFT IN THE TANK \\
\hline 6 & 4 REPS LEFT IN THE TANK \\
\hline 5 & 5 REPS LEFT IN THE TANK \\
\hline
\end{tabular}

ercises had increased from between $47 \mathrm{~s}-77 \mathrm{~s}$ to consistently in excess of 120s across all four quadrants (double leg lower, side plank left and right side, prone extension) demonstrat- ing large increases in work capacity. Basic motion analysis undertaken by the golf coach revealed reduced spinal lateral flexion and extension post impact. On one occasion during 
Table 5: Graded Return to Golf (GRTG) Protocol

Week 1:

Monday: Wedge play (half swing @ 75-85\%) - 40 balls

Wednesday: 7/8 iron play (half swing @ 75-85\%) - 40 balls

Friday: Wedge play (half swing @ 75-85\%) - 40 balls

Total: 120 balls

\section{Week 2:}

Monday: Wedge play (3/4 swing @ 75-85\%) - 40 balls

Wednesday: Mid-iron (3/4 swing @ 75-85\%) 40 balls

Friday: Par 3 10-12 holes

Total: $\sim 120$ balls

\section{Week 3:}

Monday: Wedges and/or mid-iron (full swing - 80-95\%) - 50 balls

Wednesday: Long Iron / Wood / Driver (full swing - 80-90\%) - 20 balls

Monday: Par 3 course $\sim 12-15$ holes

Total: $\sim 120$ balls

\section{Week 4:}

Monday: Wedge play (full swing - 80-90\%) - 40 balls or Par 3 course $~ 10-12$ holes

Wednesday: Long Iron / Wood / Driver (full swing - 80-90\%) - 40 balls

Friday: Par 3 course $\sim 18$ holes

Total: $\sim 150$ balls

$\%$ of intensity guided by length of backswing and \% of max club head speed

e.g. half swing @ 75-85\% swing speed.

the reconditioning (intensification) phase the subject experienced a relapse of symptoms (pain/spasm/guarding response). The athlete was reassured (that this was to be expected) and returned to the beginning of the accumulation block and a maximum of 40 wedge half-swings per week to temporarily reduce intensity. Review 18 -months post-intervention showed no signs of further inter-vertebral slippage, and the athlete remained asymptomatic despite return to pre-injury golf volumes. In April 2019 the athlete accepted a golf scholarship at a US college.

\section{DISCUSSION}

Thus far each of the rehabilitation phases and their respective objectives have been described largely in structural terms. Although sound structurally focused mechanistic reasoning is likely to improve the manner in which interventions are designed and delivered, it is important to recognize that an observed physical change (i.e. work capacity, mobility, strength) is not necessarily due to these mechanisms alone. The existing literature supports the findings herein; that exercise-based interventions are more efficacious than many popular physical therapy alternatives (e.g. manual therapy, acupuncture etc). ${ }^{33}$ Indeed, in this case 'therapy' without the use of exercise proved consistently ineffective whereas when exercise was introduced the ath- lete improved. However, it is likely that the underpinning mechanisms for this are more general and grounded in neurophysiology and a biopsychosocial model. ${ }^{34}$ This model would attribute the athlete's observed reductions in symptoms and increased load tolerance herein to reductions in catastrophising and fear avoidant behaviours, and improved self-efficacy. It is thought this ultimately leads to reductions in pain as it delivers greater movement confidence and positively reinforces physical activity. This in turn promotes recovery through a number of proposed mechanisms: 1) reassurance through reduced perceived threat and decreased sensitisation through neuromodulation, 2) mechanotransduction, 3) reduced nociceptor activity, and 4) improved immune response through increases in anti-inflammatory cytokines. ${ }^{33-35}$ Therefore if we consider the phase by phase outcomes of the rehabilitation program mechanistically, the progression of hip hinging may have acted as a form of graded exposure (progressing the ROM, time under tension, net volume or intensity in line with the athlete's pain or apprehension), or the positive response could be attributed to mechanotransduction and associated tissue repair in line with principles of mechanotherapy in response to loading the approximate region. ${ }^{36}$

Realistically more than one mechanism is likely responsible for the successful outcome, for instance early graded exposure dampened the highly sensitive pain/apprehension 
response and the graded activity of the reconditioning program provided the subject with the necessary physical capacities to stabilise and support the spine. There has been much debate within the last two decades around the structurally-focused rationale for enhancing trunk muscle function to support spinal stability, recently outlined in the thorough critical review by Wirth and colleagues. ${ }^{37}$ In particular the common categorising of the trunk musculature into "deep" and "superficial" has been challenged. ${ }^{37}$ Further, the view of increased activity of the "deep" muscles (i.e. transverse abdominis) being critical for spinal stability, and the notion that these muscles are best or only achieved with low-load tasks, has been debunked. ${ }^{38-47}$ In some ways this challenges the trunk training strategy (Figure 3) deployed herein - prioritising control exercises in phase 1 , however when we again consider the biopsychosocial model, starting the rehabilitation program with lower-load exercises would be viewed sensible graded activity. Perhaps in light of this research it could be argued that beyond the acute and sub-acute phases the micro-program was of little added value in structural terms. However, it did likely remain a helpful break and local muscle fatigue management strategy during putting practices.

Another probable key factor allowing the subject to return to pre-injury golf volumes was the technical changes shaped by the golf coach, which ultimately reduced the demand on the spinal stabilisers. Indeed, McCarroll et al ${ }^{48}$ identified degree of lateral spinal flexion as an indicator of lumbar spine stress in the golf swing so a reduction in lateral shear forces is a plausible explanation for the athlete's newfound tolerance to the game. It is also probable that education of the athlete throughout the process, specifically around load management was important in his ability to sustain ongoing participation in the sport.

\section{CONCLUSION}

Regardless of underpinning mechanisms, this case report highlights the benefits of a graded program of exercisebased rehabilitation over the typically prescribed " 12 weeks rest" prior to a return to the provocative activity. It also supports existing evidence that passive therapeutic approaches should only be used as an adjunct to exercise, if at all, in the management of this condition. Recovery from spondylolysis can be a long and slow process, in this case a program of exercise rehabilitation with clear objectives and milestones had a positive effect on recovery whereas previous periods of rest and passive therapy alone had not facilitated a successful return to golf. It is therefore stressed that to deem a non-surgical rehabilitation 'unsuccessful' or 'failed' in the management of this condition, clinicians should ensure that (long-term) exercise was included in the conservative approach. In this case having the patience and diligence to adhere to such an approach avoided a surgical intervention which aside from being a major life stress, may well have prevented further participation in golf and made his scholarship offer unlikely.

\section{CONFLICTS OF INTEREST}

The authors report no conflicts of interest

Submitted: June 10, 2020 CDT, Accepted: October 03, 2020 CDT 


\section{REFERENCES}

1. Morita T, Ikata T, Katoh S, Miyake R. Lumbar spondylolysis in children and adolescents. J Bone Joint Surg. 1995;77(4):620-625. doi:10.1302/0301-620x.77b $\underline{4.7615609}$

2. Lawrence KJ, Elser T, Stromberg R. Lumbar spondylolysis in the adolescent athlete Phys Ther Sport. 2016;20:56-60.

3. McCleary MD, Congeni JA. Current concepts in the diagnosis and treatment of spondylolysis in young athletes. Curr Sports Med Rep. 2007;6(1):62-66.

4. Chosa E, Totoribe K, Tajima N. A biomechanical study of lumbar spondylolysis based on a threedimensional finite element method. J Orthop Res. 2004;22(1):158-163. doi:10.1016/s0736-0266(03)0016 $\underline{0-8}$

5. Masci L, Pike J, Malara F, et al. Use of one-legged hyperextension test and magnetic resonance imaging in the diagnosis of active spondylolysis. Br J Sports Med. 2006;40(11):940-946. doi:10.1136/bjsm.2006.03 0023

6. Donaldson LD. Spondylolysis in elite junior-level ice hockey players. Sports Health. 2014;6(4):356-359. doi:10.1177/1941738113519958

7. Robinson PG, Murray IR, Duckworth AD, et al. Systematic review of musculoskeletal injuries in professional golfers. Br J Sports Med. 2018;0:1-6.

8. Ruiz-Cotorro A, Balius-Matas R, Estruch-Massana $\mathrm{A}$, et al. Spondylolysis in young tennis players. $\mathrm{Br} \mathrm{J}$ Sports Med. 2006;40(5):441-446. doi:10.1136/bjsm.20 05.023960

9. Yamaguchi KT Jr, Skaggs DL, Acevedo DC, et al. Spondylolysis is frequently missed by MRI in adolescents with back pain. J Child Orthop. 2012;6:237-240.

10. Purcell L, Michell L. Low back pain in young athletes. Sports Health. 2009;1(3):212-222. 7/1941738109334212

11. Tawfik S, Phan K, Mobbs RJ. The incidence of pars interarticularis defects in athletes. Global Spine J. 2019:1-13.

12. Mclean J, Andrisani J. The X-Factor Swing: And Other Secrets to Power and Distance. New York: Harper Collins;1996
13. Hume PA, Keogh J, Reid D. The role of biomechanics in maximising distance and accuracy of golf shots. Sport Med. 2005;35(5):429-449. doi:10.216 5/00007256-200535050-00005

14. Myers J, Lephart S, Tsai Y-S, Sell T, Smoliga J, Jolly $\mathrm{J}$. The role of upper torso and pelvis rotation in driving performance during the golf swing. J Sports Sci. 2008;26(2):181-188. doi:10.1080/02640410701373 $\underline{543}$

15. Sorbie GG, Gu Y, Baker JS, Ugbolue UC. Analysis of the X-Factor and X-Factor stretch during the completion of a golf practice session in low-handicap golfers. Int J Sport Sci Coaching. 2018;13(6):1001-1007. doi:10.1177/174795411879133 $\underline{0}$

16. Langdown B, Burnett S, Jones N, et al. Practice and Tournament Volumes of Young Golfers in Regional and National Squads. Abbotsford, BC, Canada: World Scientific Congress of Golf; 2018.

17. Gabbett TJ. The training-injury prevention paradox: Should athletes be training smarter and harder? Br J Sports Med. 2016;50(5):273-280. doi:10.1 136/bjsports-2015-095788

18. Overley SC, McAnany SJ, Andelman S, et al. Return to play in adolescent athletes with symptomatic spondylolysis without listhesis: A metaanalysis. Global Spine J. 2018;8(2):190-197. doi:10.117 $\underline{7 / 2192568217734520}$

19. Sundell CG, Jonsson H, Ådin L, Larsén K. Stress fractures of pars interarticularis in adolescent athletes a classification system with MRI and CT enabling evaluation of the healing process. J Exerc Sports Orthop. 2018;5(1):1-6. doi:10.15226/2374-690 4/5/1/00169

20. Panteliadis P, Nagra NS, Edwards KL, Behrbalk E, Boszczyk B. Athletic population with spondylolysis: Review of outcomes following surgical repair or conservative management. Global Spine J. 2016;6(6):615-625. doi:10.1055/s-0036-1586743

21. Hodges PW. Pain and motor control: From the laboratory to rehabilitation. J Electromyogr Kinesiol. 2011;21(2):220-228. doi:10.1016/j.jelekin.2011.01.002

22. van Dieën JH, de Looze MP. Directionality of anticipatory activation of trunk muscles in a lifting task depends on load knowledge. Exp Brain Res. 1999;128(3):397-404. doi:10.1007/s002210050860 
23. Akuthota V, Ferreiro A, Moore T, Fredericson M. Core stability exercise principles. Curr Sports Med Rep. 2008;7(1):39-44. doi:10.1097/01.csmr.000030866 $\underline{3.13278 .69}$

24. Diedrichsen J, Shadmehr R, Ivry RB. The coordination of movement: Optimal feedback control and beyond. Trends Cogn Sci. 2010;14(1):31-39. doi:1 0.1016/j.tics.2009.11.004

25. Silfies SP, Squillante D, Maurer P, Westcott S, Karduna AR. Trunk muscle recruitment patterns in specific chronic low back pain populations. Clin Biomech. 2005;20(5):465-473. doi:10.1016/j.clinbiome ch.2005.01.007

26. van Dieën JH, Selen LPJ, Cholewicki J. Trunk muscle activation in low-back pain patients, an analysis of the literature. J Electromyogr Kinesiol. 2003;13(4):333-351. doi:10.1016/s1050-6411(03)0004 $\underline{1-5}$

27. van Dieën JH, Cholewicki J, Radebold A. Trunk muscle recruitment patterns in patients with low back pain enhance the stability of the lumbar spine. SpineJ. 2003;28(8):834-841. doi:10.1097/01.brs.00000 $\underline{58939.51147 .55}$

28. Adams M, Dolan P. How to use the spine, pelvis, and legs effectively in lifting. In: Vleeming A, Mooney V, Stoeckart R, eds. Movement, Stability and Lumbopelvic Pain: Integration of Research and Therapy. 2nd ed. New York, NY: Churchill Livingstone Elsevier; 2007:167-183. https://doi.org/10.1016/b978-0443101 78-6.50013-x.

29. Marshall R, Elliott BC. Long-axis rotation: The missing link in proximal-to-distal segmental sequencing. J Sports Sci. 2000;18(4):247-254. doi:10.1 $\underline{080 / 026404100364983}$

30. Spencer S, Wolf A, Ruston A. Spinal-Exercise Prescription in Sport: Classifying Physical Training and Rehabilitation by Intention and Outcome. J Athl Train. 2012;51:10.

31. Issurin V. Block periodization versus traditional training theory: A review. J Sports Med Phys Fit. 2008;48(1):65-75.

32. Graham T, Cleather D. Autoregulation by "Repetitions in Reserve" leads to greater improvements in strength over a 12-week training program than fixed loading. J Strength Cond Res. 2019;33(6):1534-1154.

33. Chimenti RL, Frey-Law LA, Sluka KA. A mechanism-based approach to physical therapist management of pain. Phys Ther. 2018;98(5):302-314. doi:10.1093/pti/pzy030
34. Wideman TH, Sullivan MJL. Reducing catastrophic thinking associated with pain. Pain Management. 2011;1(3):249-256. doi:10.2217/pmt.11.14

35. Sluka KA, Frey-Law L, Bement MH. Exerciseinduced pain and analgesia? Underlying mechanisms and clinical translation. Pain. 2018;159:S91-7:91-97.

36. Khan KM, Scott A. Mechanotherapy: How physical therapists' prescription of exercise promotes tissue repair. Br J Sports Med. 2009;43(4):247-252. doi:10.11 36/bjsm.2008.054239

37. Wirth K, Hartmann H, Mickel C, Szilvas E, Keiner M, Sander A. Core stability in athletes: A critical analysis of current guidelines. Sports Med. 2017;47(3):401-414.

38. Lederman E. The myth of core stability. J Bodyw Mov Ther. 2010;14(1):84-98.

39. Stokes IAF, Gardner-Morse MG, Henry SM. Intraabdominal pressure and abdominal wall muscular function: Spinal unloading mechanism. Clin Biomech. 2010;25(9):859-866.

40. Stokes IAF, Gardner-Morse MG, Henry SM. Abdominal muscle activation increases lumbar spinal stability: Analysis of contributions of different muscle groups. Clin Biomech. 2011;26(8):797-803.

41. Grenier SG, McGill SM. Quantification of lumbar stability by using 2 different abdominal activation strategies. Arch Phys Med Rehabil. 2007;88(1):54-62.

42. Kavcic N, Grenier S, McGill SM. Determining the stabilizing role of individual torso muscles during rehabilitation exercises. Spine J. 2004;29(11):1254-1265.

43. Cholewicki J, VanVliet JJ 4th. Relative contribution of trunk muscles to the stability of the lumbar spine during isometric exertions. Clin Biomech. 2002;17(2):99-105.

44. McGill SM, Grenier S, Kavcic N, et al. Coordination of muscle activity to assure stability of the lumbar spine. J Electromyogr Kinesiol. 2003;13(4):353-359.

45. Stevens VK, Bouche KG, Mahieu NN, et al. Trunk muscle activity in healthy subjects during bridging stabilization exercises. BMC Musculoskelet Dis. 2006;7(1):75.

46. Vera-Garcia FJ, Elvira JLL, Brown SHM, et al. Effects of abdominal stabilization maneuvers on the control of spine motion and stability against sudden trunk perturbations. J Electromyogr Kinesiol. 2007;17(5):556-567. 
47. Stanton T, Kawchuk G. The effect of abdominal stabilization contractions on posteroanterior spinal stiffness. Spine J. 2008;33(6):694-701.
48. McCarroll JR, Rettig AC, Shelbourne KD. Injuries in the amateur golfer. Phys Sportsmed. 1990;18:122-126. 